\title{
PREVENTING CHILD SEXUAL ABUSE (CSA) IN ETHNIC MINORITY COMMUNITIES: A LITERATURE REVIEW AND SUGGESTIONS FOR PRACTICE IN AUSTRALIA
}

\author{
Pooja Sawrikar and Ilan Katz
}

Corresponding author Dr Pooja Sawrikar, School of Human Services and Social Work (HSV), Griffith University (GU), Gold Coast campus, Parklands Drive, Southport, Queensland, 4222, Australia, p.sawrikar@griffith.edu.au

Co-author Professor Ilan Katz, Social Policy Research Centre (SPRC), University of New South Wales (UNSW), Australia, ilan.katz@unsw.edu.au

Highlights • A systematic literature review on CSA and ethnic minorities was conducted • Most CSA prevention efforts are programs in the school system • In Western multicultural countries, culturally tailored programs further risk racism • Service agencies can help improve the prevention of CSA for all children • Education over disclosures and help-seeking are critical to evaluate for collectivists.

Disclaimer This manuscript has not been published elsewhere, and is not under consideration by any other journal. However, this article reports on the findings from one of six themes explored in a larger study (community awareness, prevention, disclosure, treatment needs, service delivery models, and current national service provision). Thus, content in the Introduction and Method overlaps with content in all prepared articles, but which then report on the findings of only one of the explored themes (here, prevention) making them each overall different from one another.

Acknowledgments We would like to thank Professor Fiona Arney, Professor Leah Bromfield, Dr Jen Hamer, and Professor Patrick O’Leary for their comments and feedback on an earlier version. We would also like to thank the anonymous reviewers of this article for their comments and feedback, which have been incorporated into the manuscript.

Conflict of interest There is no known conflict of interest. 


\title{
PREVENTING CHILD SEXUAL ABUSE (CSA) IN ETHNIC MINORITY COMMUNITIES: A LITERATURE REVIEW AND SUGGESTIONS FOR PRACTICE IN AUSTRALIA
}

\begin{abstract}
A systematic literature review was conducted to address the immense national gap in knowledge on child sexual abuse (CSA) and ethnic minority communities in Australia, which necessarily borrowed from overseas. One theme explored within the review was that of prevention, and it was found that school-based programs are the most common type of prevention effort. The literature also calls for 'culturally tailored' programs to avoid homogenising victims’ needs, however in Western multicultural countries like Australia there is a risk that such school-based programs heighten racism for ethnic minority children. Thus, program elements that are culturally sensitive could be incorporated into universal programs instead. Universal programs are also beneficial because they help reach many children regardless of their cultural background, help send the message that all children are equally valued and protected, help create unity and support among diverse victims, and can be further justified by three relatively stable cross-cultural findings: (i) that the prevalence of CSA is high worldwide, (ii) all children require protection irrespective of gender, and (iii) perpetrators are usually known to the victim. To help mobilise their role, service providers could co-deliver school-based programs especially to address institutional CSA within schools. They could also provide training to other health professionals to improve their identification of CSA and confidence to probe; a form of early intervention and therefore 'secondary prevention'. Overall, this review argues that the importance of family reputation in collectivist cultures needs to be taken into account when designing and evaluating prevention programs so that delays in disclosure and helpseeking due to cultural pressure are not mistaken as evidence for their ineffectiveness. The findings are significant because they help progress the 'prevention’ field in Australia where literature is essentially absent, particularly in the school and service system arenas.
\end{abstract}

\section{Keywords}

Child sexual abuse (CSA), ethnic minorities, Australia, prevention, early intervention, collectivism 


\section{PREVENTING CHILD SEXUAL ABUSE (CSA) IN ETHNIC MINORITY COMMUNITIES: A LITERATURE REVIEW AND SUGGESTIONS FOR PRACTICE IN AUSTRALIA}

\section{$1 \quad$ Introduction}

\subsection{Background: Why was this literature review conducted?}

It is acknowledged in the field that research on child sexual abuse (CSA) and ethnic minorities is substantially under-developed (Futa, Hsu, \& Hansen, 2001; Tishelman \& Geffner, 2010). This is particularly true of Australia where literature is essentially absent. For example, only one identifiable study on CSA across cultural groups based on a national sample was found in this review (Taylor \& Norma, 2013). To address this gap, a systematic literature review - necessarily borrowing from overseas to help inform the national context - was conducted. It explored several themes including that of prevention (the other themes were community awareness, disclosure, treatment needs, service delivery models, and national service provision; the results of these have been reported elsewhere). This article reports the findings on the theme of prevention in relation to two research questions (RQs): (1) what is currently known about the prevention of CSA in ethnic minority communities? and (2) what role can service agencies play to improve the prevention of CSA in ethnic minority communities? In doing so, it helps address the current immense gap in national knowledge and thus is a significant contribution to literature.

\subsection{Defining the client group: Who are ethnic minorities?}

Ethnic minorities refer to those who have a migration history and are minorities in at least one of the four main dimensions of ethnicity identified by O’Hagan (1999) - race, language, culture, and religion. Thus, they are differentiated from Indigenous people (in Australia, Aboriginal and Torres Strait Islander) and the mainstream (Anglo Saxon/Celtic Australians). They also tend to come from non-English speaking backgrounds (NESBs) and countries higher on collectivism (see ‘Theoretical framework' for more information). The term usually includes refugees and asylum seekers but is not sufficient for describing the needs and experiences of this group uniquely (Sawrikar, 2017). A synonymous term used in the national discourse is 'Culturally and Linguistically Diverse (CALD)'. However, 'ethnic minorities' is the term used here because 'CALD' only highlights issues to do with two of the four dimensions of ethnicity - culture and language (Sawrikar \& Katz, 2009).

Table 1 summarises Australia’s migrant profile (Australian Bureau of Statistics [ABS], 2016). It indicates that most overseas-born people in Australia originate from countries like the UK (North-West Europe) and many also come from New Zealand (Oceania and Antarctica), but of those from non-English speaking countries most 
are from Asia (e.g. China, India) and Southern and Eastern Europe (e.g. Italy, Greece). Australia has also seen a recent increase in the number of people from Africa, commonly entering on humanitarian visas (ABS, 2012).

Table 1: Overseas country of birth by region (ABS, 2016)

\begin{tabular}{|c|c|c|}
\hline Region of birth & Persons & $\begin{array}{l}\text { Proportion of overseas-born } \\
\text { population (\%) }\end{array}$ \\
\hline North-West Europe & $1,431,169$ & 23.2 \\
\hline South-East Asia & 872,891 & 14.2 \\
\hline North-East Asia & 789,436 & 12.8 \\
\hline Southern and Central Asia & 782,903 & 12.7 \\
\hline Southern and Eastern Europe & 657,698 & 10.7 \\
\hline Oceania and Antarctica(a) & 657,696 & 10.7 \\
\hline Sub-Saharan Africa & 317,182 & 5.1 \\
\hline Middle East & 303,089 & 4.9 \\
\hline Northern America & 129,704 & 2.1 \\
\hline South America & 114,599 & 1.9 \\
\hline Other Americas $^{\mathrm{a}}$ & 21,751 & 0.4 \\
\hline North Africa & 70,994 & 1.2 \\
\hline Total $^{\mathrm{b}}$ & $6,163,667$ & 100 \\
\hline
\end{tabular}

Source: Census of Population and Housing, 2016; a - Other Americas includes Central America, Caribbean and

Americas, nfd; b - Total includes Inadequately described, At sea, and North Africa and the Middle East, nfd.

\section{Theoretical framework: Why use individualism and collectivism?}

'Collectivism' sees the basic unit of society to be the family, whereas ‘individualism' which sees the individual to be the basic unit of society (Hofstede, 1980). Thus, collective cultures value social order, harmony, support and roles; the family provides security in exchange for loyalty and obedience; inequality (usually based on age and gender) is seen as appropriate and acceptable; and members tend to be more homogenous as deviations from the norm are not tolerated as greatly (Bond, 2002; Triandis, 1990). On the other hand, individualistic cultures value independence, autonomy, initiative and uniqueness; emphasise that individuals have the right and 
responsibility to look after themselves; stress horizontal relationships based on equality; and tolerate deviations from the norm to a greater extent (Bond, 2002; Triandis, 1990).

Hofstede $^{1}$ (2001) shows that the US, Australia, UK, Canada, and New Zealand rank (in order) highest on individualism (with scores on individualism [IDV] ranging from 91 to 79). Western European countries such as Belgium, France, and Germany rank next highest (with scores ranging from 75 to 67). The remaining parts of the world such as East Europe, Asia, South America, Middle East, and Sub-Saharan Africa all rank higher on collectivism (with scores on IDV ranging from 65 to 6). Table 2 contains more information. The implication of this data is that many ethnic minorities in Western countries like Australia originate from non-Western countries high on collectivism. Moreover, cultural values, norms, beliefs, and traditions such as collectivism remain pervasive after migration - even among well-established migrant groups and across generations - because in the dynamic process of acculturation there is a continuous management of the need to adapt to the new culture against a competing need to preserve the culture of origin (Berry, 1980). Thus, collectivism remains a pertinent characteristic among ethnic minorities.

Table 2: Individualism (IDV) scores by country ${ }^{2}$

\begin{tabular}{|c|c|c|c|c|c|c|c|}
\hline Country & IDV & Country & IDV & Country & IDV & Country & IDV \\
\hline Unites States & 91 & Czech Republic & 58 & United Arab Emirates & 38 & Sierra Leone & 20 \\
\hline Australia & 90 & Austria & 55 & Turkey & 37 & Singapore & 20 \\
\hline United Kingdom & 89 & Hungary & 55 & Uruguay & 36 & Thailand & 20 \\
\hline Netherlands & 80 & Israel & 54 & Greece & 35 & El Salvador & 19 \\
\hline New Zealand & 79 & Spain & 51 & Philippines & 32 & South Korea & 18 \\
\hline
\end{tabular}

\footnotetext{
${ }^{1}$ The website from which this data has been drawn says, "National cultures can be described according to the analysis of Geert Hofstede. These ideas were first based on a large research project into national culture differences across subsidiaries of a multinational corporation (IBM) in 64 countries. Subsequent studies by others covered students in 23 countries, elites in 19 countries, commercial airline pilots in 23 countries, upmarket consumers in 15 countries, and civil service managers in 14 countries. Together these studies identified and validated four independent dimensions of national culture differences, with a fifth dimension added later: Power Distance, Individualism, Masculinity, Uncertainty Avoidance, and Long-Term Orientation”.

${ }^{2}$ http://www.clearlycultural.com/geert-hofstede-cultural-dimensions/individualism/
} 


\begin{tabular}{|c|c|c|c|c|c|c|c|}
\hline Italy & 76 & India & 48 & Mexico & 30 & Taiwan & 58 \\
\hline Belgium & 75 & Argentina & 46 & Ethiopia & 27 & Peru & 16 \\
\hline Denmark & 74 & Japan & 46 & Kenya & 27 & Costa Rica & 15 \\
\hline France & 71 & Iran & 41 & Portugal & 27 & Indonesia & 14 \\
\hline Sweden & 71 & Jamaica & 39 & Tanzania & 27 & Pakistan & 14 \\
\hline Ireland & 70 & Brazil & 38 & Zambia & 27 & Colombia & 13 \\
\hline Norway & 69 & Egypt & 38 & Malaysia & 26 & Venezuela & 12 \\
\hline Switzerland & 68 & Iraq & 38 & Hong Kong & 25 & Panama & 11 \\
\hline Germany & 67 & Kuwait & 38 & Chile & 23 & Ecuador & 8 \\
\hline South Africa & 65 & Lebanon & 38 & China & 20 & Guatemala & 6 \\
\hline
\end{tabular}

In the context of CSA, the heuristic dichotomy of individualism and collectivism has utility because it is associated with disclosure and help-seeking. Specifically, they could be delayed in ethnic minority communities because of the definitive value for the family collective and its needs, and therefore an all-pervading need to protect the family’s name/ reputation and community standing. Disclosure and help-seeking are indicators of the effectiveness of prevention programs, however delays in them due to cultural pressure to protect the family's 'face' could be mistakenly seen as evidence for their ineffectiveness ${ }^{3}$. Thus, the theoretical framework is useful for being able to interpret and understand the needs and experiences of children and families from ethnic minority communities when they engage with prevention programs.

Individualism and collectivism are theoretical constructs that vary on a continuum from high to low; they are not mutually exclusive categories. Therefore, if a country is high on 'individualism' this does not then mean that it has no collectivist elements or characteristics. Thus, the theoretical framework of individualism and collectivism is only being used here to help highlight the centrality of family, reputation, silence, and exclusion among victims/survivors of CSA from ethnic minority communities, but not to minimise their importance in groups

\footnotetext{
${ }^{3}$ Education programs that lead to disclosures and help-seeking help prevent re-traumatisation. However, education that reduces incidence helps prevent traumatisation. Thus, disclosures and help-seeking are not the only indicators of the success of preventative education programs because they presuppose the occurrence of abuse.
} 
heuristically categorised as 'individualistic'. That is, the framework provides a culturally relevant 'lens' for making sense of the needs and experiences of ethnic minorities, which is necessary when attempting to identify how best to protect children in these communities.

Thus, patterns of silence and exclusion to protect family reputation are fundamental in collectivist cultures but not exclusive to them. Further, the theoretical framework is but one way to conceptualise culture and therefore is seen to be necessary but not sufficient for understanding cross-cultural differences in the experience of CSA. Indeed, it is argued here that the framework should not be definitively relied on; these broad cultural categories need to be used with vigilance, ensuring that the beliefs comprising these stereotypes are accurate, do not perpetuate harm or disadvantage to groups, and are questioned when applied to individual situations (Sawrikar, 2017). This is particularly critical for clinical practice because stereotyped assumptions about culture can result in inappropriate and even harmful outcomes (Owusu-Bempah \& Howitt, 2000). These themes and issues are described in more detail under 'Results'.

\section{$2 \quad$ Method}

\subsection{Approach}

The relevant scholarly literature was obtained by following the Preferred Reporting Items for Systematic Reviews and Meta-Analyses (PRISMA) process. Figure 1 contains the PRISMA flow diagram (Moher, Liberati, Tetzlaff, Altman, \& The PRISMA Group, 2009).

Literature was first sourced from a number of relevant databases. These were: Australian Public Affairs FullText, Health and Society Database, Informit Family and Society Collection, Informit Health Collection, Informit Humanities and Social Sciences Collection, Multicultural Australia and Immigration Studies, ProQuest Family Health, PsycINFO, Scopus, Social Services Abstracts, and Sociological Abstracts.

A series of search terms related to the two keywords - 'child sexual abuse' and 'ethnic minorities' - were then combined. The search terms for the first keyword were: sexual abuse, sexual harassment, sexual exploitation, molestation, rape, indecent assault, sexual violence, and gender violence. The search terms for the second keyword were: culture (cultur*), race (rac*), culturally and linguistically diverse (CALD), non-English speaking background (NESB), ethnic minority/ies (ethni*), migrant, immigrant, refugee, asylum seeker, of color/colour, and community. 
Searches were then limited to 2000-2016, although seminal research was not excluded and was sourced from the reference lists of the recent articles. They were also limited to those in English, peer-reviewed, with the fulltext available, and only about sexual abuse experienced in childhood by someone from an ethnic minority background (i.e. ethnic minorities in Western countries or about non-Western countries).

Figure 1: PRISMA flow diagram
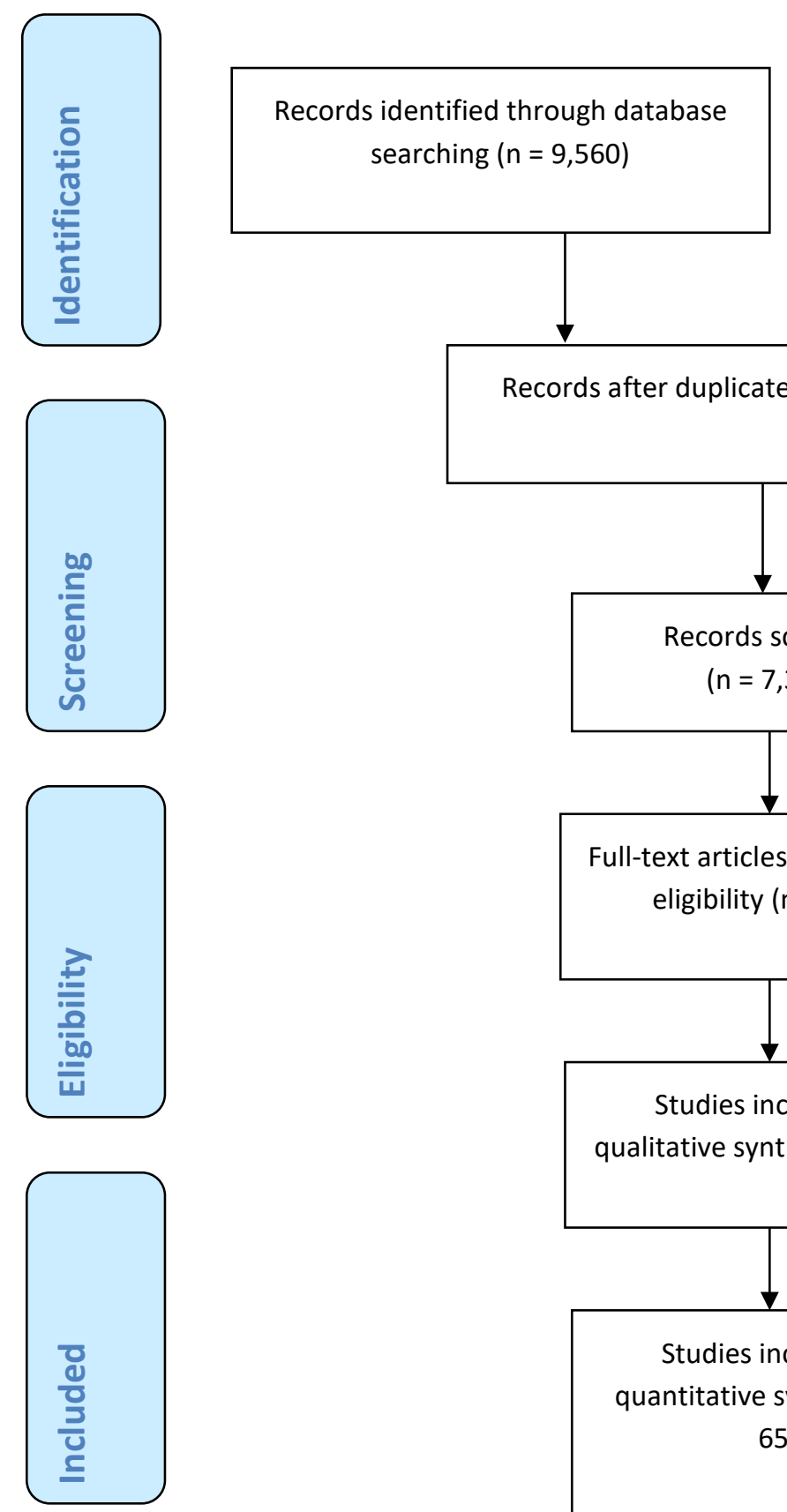

Additional records identified through other sources $(n=0)$

Records after duplicates removed $(n=7,363)$

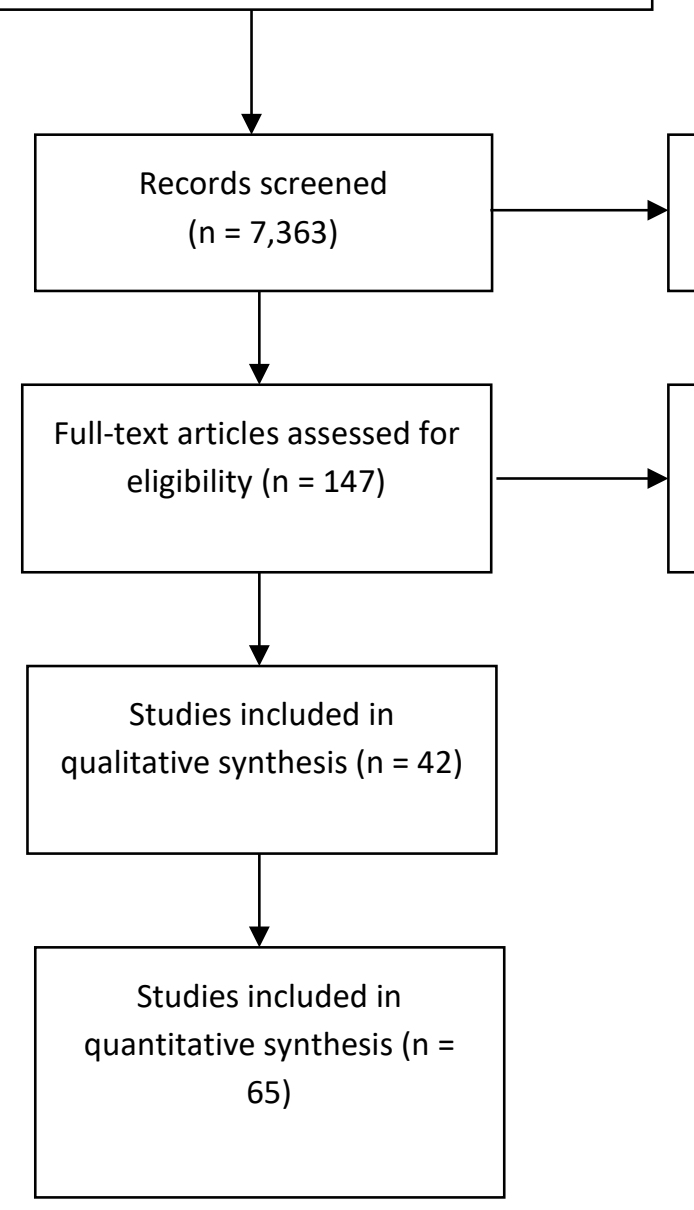

Full-text articles excluded, with reasons $(n=12)$ 
Literature was excluded if it only pertained to Native Americans and African Americans to address a priori issues to do with the transferability of findings from Indigenous groups in other Western countries and/or minority groups not represented in Australia. Literature only pertaining to Latina/Hispanic Americans was also excluded on the grounds that they form a large and significant minority group in the US and so their needs and experiences could be quite specific to that context. However, literature that addressed groups in addition to Native, African, and Latina/Hispanic Americans - for example, Asian-Americans (as Asians are represented in Australia) - were included in the review, so that the former groups were not wholly disregarded. This is particularly helpful for ensuring that racial and other ethnic barriers common among all minorities are represented to some extent in the review.

Applying these various inclusion/exclusion criteria left a total of 135 records eligible for full review. Of these, 42 primarily used qualitative methodologies (e.g. interviews, focus groups, etc.), 65 primarily used quantitative methodologies (e.g. surveys, meta-analyses, etc.), eight used a mixed-methods approach (counted under the ‘Quantitative’ records), and 28 used secondary analyses (e.g. literature reviews, commentaries, etc.). As the secondary analysis records did not use either qualitative or quantitative methodologies, they do not appear in the flowchart. Only articles relevant to the two research questions of this article have been cited here, and Appendix A contains a summary of those that directly addressed the theme of prevention; identifying the ethnic groups investigated in the study, their method, and whether it could be deemed rigorous.

\section{$2.2 \quad$ Strengths and weaknesses}

The process for obtaining the literature was systematic, comprehensive, and exhaustive. Each theme identified in the body of literature was also identified, described, and analysed (while keeping in mind a need for brevity). These themes have been described in the form of a narrative review (under 'Results'), and thus thematic analysis is merged with description. Nevertheless, some methodological weaknesses need to also be noted.

The first is that because the body of literature on CSA among ethnic minority communities is small, and on the specific topic of prevention even smaller, several different races, cultures, languages, and religions have been grouped here together; what Fontes (1993) calls ‘ethnic lumping’. While minorities do share some experiences such as language needs, experiences of racism and discrimination, and a collectivist cultural background, making results for one group reasonably generalisable to another, it ultimately and falsely homogenises each groups’ needs because it fails to take into account more nuanced traditions, beliefs, values, and norms. The 
limited literature also constrains being able to offer evidence-based principles of best practice for improving prevention (an indirect aim of RQ 1 and the direct aim of RQ 2); only suggestions can be made.

Another limitation is that the review needed to borrow from international literature, most especially the US and UK, but this poses issues for the transferability of findings to Australia. This issue was somewhat addressed by excluding literature that related solely to groups not represented in Australia (e.g. Native and African Americans). Reasonable comparisons can be made with other Western countries, however minorities do still have different 'ethnic profiles' across them, with different specific groups and sizes comprising their migrant community as well as reasons for their migration to these countries which all affect their socio-cultural and political standing there (Sawrikar \& Katz, 2008). Thus, caution still needs to be exercised.

There is also the issue that themes identified in the literature from non-Western countries may only partially help explain the needs and experiences of ethnic minorities in Western countries; the migration experience will interact with those cultural factors in such a unique way that literature from 'back home' may become limited or even irrelevant. Moreover, literature from non-Western countries was not equally represented; more was about East Asians and South Asians, sub-Saharan and South Africans, and Arabs and Jews, so the experiences of other groups are even less well documented. This poses further issues for transferability to the Australian context; it highlights that the current non-Western literature is helpful but not sufficient to cover the breadth of applicability required.

Finally, it is important to point out that only including English-language articles is problematic because it leaves out important voices from within countries of origin, which future research by multilingual scholars can and should address. Overall, however, the inclusion of articles from diverse backgrounds is a global approach consistent with and required for issues that address multiculturalism. Indeed, the dearth of research in Australia meant that this review had to borrow from overseas to be able to begin national knowledge-building.

\section{$3 \quad$ Results}

\subsection{RQ 1 - What is currently known about the prevention of CSA in ethnic minority communities?}

The literature indicates that "prevention includes a range of approaches at the policy, community, and interpersonal level, (but because) children need to develop self-protective skills, (they) remain the first and foremost targets of interventions” (Krahe \& Knappert, 2009, p. 322). Kenny and Wurtele (2012) similarly note that "previous efforts to prevent child sexual abuse have primarily focused on educating children, less frequently 
on informing parents/caretakers, and infrequently on modifying environments in which child sexual abuse occurs” (p. 362). ${ }^{4}$

Thus, prevention efforts tend to be in school-based programs, which have been shown to be effective arenas for the prevention of CSA (Chen, Dunne, \& Han, 2007); they can “reach a large number of children and are therefore a practical and cost effective way to disseminate prevention skills and concepts” (Baker, Gleason, Naai, Mitchell, \& Trecker, 2013, p. 168). Indeed, studies show that the majority of CSA cases are with children between eight and 10 years (Choi et al., 2015), so 'getting in early' is critical. While there is a "challenge to design intervention measures that are appropriate and effective in young children” (Krahe \& Knappert, 2009, p. 322) for all groups, the literature suggests that for ethnic minority communities two types of programs may be needed - universal and culturally tailored.

\subsubsection{Universal school-based prevention programs}

In multicultural countries like Australia, it is important to be able to reach as many children as possible regardless of their cultural background. This need warrants the use of universal (or non-culturally tailored) prevention programs. They also help send the message that CSA is seen by (Australian) governments as a universal problem, and that as such all children are intended to be equally protected. That is, they help prevent any unintended consequence that minority children feel targeted or that mainstream children feel excluded by ‘culturally tailored’ programs, as if CSA were only relevant to ethnic minority communities. Universal programs that emphasise that responses to victimisation such as traumatic sexualisation, betrayal, powerlessness, and stigmatisation (Finkelhor \& Browne, 1985) occur independent of ethnicity, may also help create a sense of unity among victims/survivors from diverse backgrounds and therefore boost peer-based sources of support.

Thus, the possible benefits of universal programs - reaching as many children as possible, making children feel equally protected, and creating unity and support among diverse victims - help justify their importance.

\footnotetext{
${ }^{4}$ Prevention in the form of outreach educational programs directed at parents/guardians within ethnic minority communities is discussed elsewhere (see Sawrikar \& Katz, 2017). Literature on modifying environments where CSA occurs has not been reviewed here because only one such article was identified from the PRISMA process (see Choi, Choo, Choi, \& Woo, 2015 who discuss 'situational crime prevention'). Thus, the focus of this paper is on school-based programs.
} 
However, there are three other relatively stable findings in the literature that further help justify their use: (i) the prevalence of CSA is high worldwide, (ii) all children require protection irrespective of gender, and (iii) perpetrators are usually known to the victim. There are important variations within these three trends, which have been described in more detail below. They do not directly relate to the theme of prevention but are still critical to acknowledge. Overall, however, they suggest that there is a core set of elements to the experience of CSA which help warrant the use of universal programs.

\subsubsection{Prevalence of CSA worldwide}

Unfortunately, a national study on the prevalence of CSA in Australia has not been conducted (Mathew et al., 2016). As a result, cross-cultural differences between Indigenous, Anglo, and various ethnic minority groups in Australia is also not known. While there is no direct causal link between prevalence in various groups in Australia and prevalence in countries of origin for various minority groups, the international literature may be somewhat helpful in gauging national prevalence assuming at least some correlation.

Only a few studies have attempted to assess the international prevalence of CSA and identify characteristics of countries with high and low prevalence rates (Finkelhor, 1994; Pereda, Guilera, Forns, \& Gomez-Benito, 2009; Stoltenborgh, van Ijzendoorn, Euser, \& Bakermans-Kranenburg, 2011). However, this data is difficult to interpret for a number of reasons.

First, there are issues to do with the cross-cultural validity of instruments, which need to balance pressures between being 'emic' - valuing social constructionism - and being 'etic' - emphasising universalism (Collings, Lindblom, Madu, \& Park, 2009; Wang \& Heppner, 2011). Different cultures define and operationalise CSA differently (e.g. Al-Fayez, Ohaeri, \& Gado, 2012; Capri, 2013; Gwirayi, 2013; Haboush \& Alyan, 2013; Ko \& Koh, 2007; Mansbach-Kleinfeld, Ifrah, Apter, \& Farbstein, 2015; Sil \& Soo, 2008; Wang \& Heppner, 2011), and the extent to which this reflects ecological validity or a hindrance to making cross-cultural comparisons is yet to be more fully studied. Capri (2013) says, for example, “although there have been calls for risk factors that are cross-culturally recognisable, this might obscure the South African context” (p. 35). More broadly, "a relativistic approach to addressing CSA across cultures risks failing to protect children ... (because) culturally and socially determined aspects of what constitutes CSA do not undermine children's absolute need for protection from harm” (Pasura, Jones, Hafner, Maharaj, Nathaniel-DeCaires, \& Johnson, 2012, p. 211-212). 
Thus, studies vary in the age cut-offs they use (usually anywhere between 12-18 years), reflecting their countries'/cultures' conceptualisation of both 'childhood' and 'abuse'. One study in Jamaica, for example, found that men "considered childhood as ending at 12 years” (Pasura et al., 2012, p. 208). Another study in Zimbabwe "found that men do not seem to regard sex with a physically developing girl as a crime ... (They) consider a girl’s physical maturity as a sign of her readiness to have sex” (Madu \& Peltzer, 2000, p. 264). Studies and countries also vary on whether they include non-contact CSA such as exhibitionism and sexual propositions (Pereda et al., 2009). Generally, the stricter/narrower the definition, as is often the case in European countries like Finland and France that define CSA as incest or rape, the lower the prevalence (Jewkes, Dunkle, Nduna, Jama, \& Puren, 2010; Pereda et al., 2009). Cross-cultural studies also vary in whether they include differences in age between the victim and perpetrator, usually defined as at least five years (Jewkes et al., 2010). Finally, some studies may not even use a validated instrument to assess CSA (Ji, Finkelhor, \& Dunne, 2013).

Overall, the lack of international consensus regarding the definition of CSA leads to differences in the way it is operationalised and thus difficulties in comparing prevalence data with confidence. This occurs despite Finkelhor's (1994) long-standing call for the use of “instruments with international comparison in mind” (cited in Al-Fayez et al., 2012, p. 54). Still, although studies vary in their definition of CSA, along the lines of contact, violence, and severity, they all include its definitive element of non-consent. They also all collect data on whether the perpetrator was known, and they "all agree that CSA is a traumatic experience that should be given considerable clinical and research attention” (Walker, Hernandez, \& Davey, 2012, p. 385-386). Indeed, cultures can vary quite considerably in their conceptualisations of the other types of child maltreatment (physical abuse, emotional abuse, chronic neglect, and inadequate supervision; Sawrikar, 2017), but, as Elliot, Tong, and Tan (1997) put it, “despite discrepancies in child-rearing practices and definitions of child abuse, most cultures seem to agree on what constitutes sexual abuse, voicing strong disapproval for such behaviour toward children” (cited in Kenny \& McEachern, 2000, p. 907).

Another issue that affects the interpretation of prevalence data is recall (Lam, 2014; Okur, van der Knaap, \& Bogaerts, 2015), especially of “experiences that are very difficult to report” (Li, Ahmed, \& Zabin, 2012, p. S50). Retrospective self-report studies are liable to criticism from researchers looking for stricter empirical rigour, and who call for the use of longitudinal studies and population-based cohort studies to improve accuracy in data (Mansbach-Kleinfeld et al., 2015; Stewart, 2005). Indeed, Stoltenborgh et al. (2011) found that the prevalence rates in self-report studies "was 30 times higher than the rate of informant studies (127 per 1000 children vs. 4 
per 1000 children) ... and randomised as opposed to convenience samples are (also) associated with lower estimates” (p. 87-88).

Developmental/language factors also play a role in making sense of prevalence data. "Language can add to the problem of accurate disclosure and reporting in minority groups where English is not the primary language” (Kenny \& McEachern, 2000, p. 918), but “children’s understanding of child abuse, however ‘adult-like’ it may appear, is nevertheless still constrained by their developmental stage, especially for younger children” (Chan, Lam, \& Shae, 2011, p. 169). Thus, they may not have "the language sophistication nor the personal experience for a full understanding of what CSA relationships entail” (Shalhoub-Kevorkian, 1999, p. 1277, cited in Usta \& Farver, 2010, p. 366).

Finally, disclosure is associated with shame, guilt, embarrassment, social desirability, and fear of reprisal, which all lead to significant under-reporting (Yoshihama \& Horrocks, 2010; Shalhoub-Kevorkian, 2005). "In general, it is believed that as many as $80 \%$ of sexual abuse cases are not reported and (that) the actual incidence is much higher than the statistics reflect” (Kenny \& McEachern, 2000, p. 907). “Collings, Giffiths, and Kumalo (2005) estimated that the nondisclosure rate in their study varied from 33-92\% for girls and from 42-100\% for boys” (cited in Lam, 2014, p. 769). Thus, "reported cases only constitute the tip of the iceberg” (Mathews, Abrahams, \& Jewkes, 2013, p. 639) because “many survivors of CSA are emotionally manipulated into a 'conspiracy of silence"” (Vermeulen \& Greeff, 2015, p. 556).

Despite all these challenges in cross-cultural research, the global prevalence of CSA is still high. Using systematic research methods, Stoltenborgh et al. (2011) report a global prevalence at 11.8\% "based on 331 independent samples with a total of 9,911,748 participants” (p. 87). Pereda et al. (2009), who recently reassessed Finkelhor's (1994) seminal study, further report that across 21 countries $30 \%$ of studies reported child sexual abuse prevalence rates at above 30\%. More specifically, Finkelhor (1994) reported prevalence rates of 10-20\% in various European countries and Canada (for women). The study by Pereda et al. (2009) supports these findings but also found similar rates in the Americas (El Salvador and the US) and Asia (China, New Zealand, and Singapore). Finkelhor (1994) found higher prevalence rates in other European countries, as well as in Australia, Costa Rica, Dominican Republic, New Zealand, South Africa, and the US, whereas the study by Pereda et al. (2009) adds Great Britain, Israel, Switzerland, and Turkey to this list. Thus, "child sexual abuse remains an international problem” (Pereda et al., 2009, p. 336-337), cutting across all groups in society. Table 3 summarises findings from the review studies conducted by Finkelhor (1994) and Pereda et al (2009); 
specifically, the value or range of reported prevalence per 100 is identified, rounded to the nearest whole number. Rates above $30 \%$ are bolded.

Table 3: Prevalence of reported CSA per 100 in two international review studies (Finkelhor, 1994; Pereda et al., 2009)

\begin{tabular}{|c|c|c|c|c|}
\hline \multirow[t]{2}{*}{ Country } & \multicolumn{2}{|c|}{ Finkelhor (1994) } & \multicolumn{2}{|c|}{ Pereda et al (2009) } \\
\hline & Women & Men & Women & Men \\
\hline Australia & 28 & 9 & 39-45 & 19 \\
\hline Austria & 36 & 19 & N/A & N/A \\
\hline Belgium & 19 & - & N/A & N/A \\
\hline Canada & 18 & 8 & 13 & 4 \\
\hline China & N/A & $\mathrm{N} / \mathrm{A}$ & $7-17$ & $4-11$ \\
\hline Costa Rica & 32 & 13 & N/A & N/A \\
\hline Denmark & 14 & 7 & N/A & N/A \\
\hline Dominican Republic & 33 & 33 & & \\
\hline El Salvador & N/A & N/A & 17 & - \\
\hline Finland & 7 & 4 & 1 & 1 \\
\hline France & 8 & 5 & 1 & 1 \\
\hline Germany & 10 & 4 & N/A & N/A \\
\hline Greece & 16 & 6 & $\mathrm{~N} / \mathrm{A}$ & N/A \\
\hline Great Britain & 12 & 8 & $13-21$ & 11 \\
\hline Ireland & 7 & 5 & N/A & N/A \\
\hline Israel & N/A & N/A & 31 & 16 \\
\hline Jordan & $\mathrm{N} / \mathrm{A}$ & N/A & - & 27 \\
\hline Malaysia & N/A & N/A & 8 & 2 \\
\hline Morocco & $\mathrm{N} / \mathrm{A}$ & $\mathrm{N} / \mathrm{A}$ & 9 & - \\
\hline Netherlands & 33 & - & N/A & N/A \\
\hline New Zealand & 32 & - & 17 & 3 \\
\hline Norway & 19 & 9 & 19 & 4 \\
\hline
\end{tabular}




\begin{tabular}{|l|c|c|c|c|}
\hline Portugal & N/A & N/A & 3 & 3 \\
\hline Singapore & N/A & N/A & 16 & - \\
\hline South Africa & $\mathbf{3 4}$ & 29 & $\mathbf{3 5 - 5 3}$ & 10 \\
\hline Spain & 23 & 15 & 15 & 3 \\
\hline Sweden & 9 & 3 & 13 & $\mathbf{6 0}$ \\
\hline Switzerland & 11 & 3 & $\mathbf{1 9 - 4 0}$ & - \\
\hline Turkey & N/A & N/A & $\mathbf{1 7 - 4 9}$ & $4-14$ \\
\hline United States & 27 & 16 & & \\
\hline
\end{tabular}

N/A - Study not conducted in that country.

\subsubsection{Gender differences}

The research indicates that females are generally more at risk of CSA than males. According to the World Report on Violence and Health by the World Health Organisation [WHO], "sexual violence occurs throughout the world. Although in most countries there has been little research conducted on the problem, available data suggest that in some countries nearly one in four women may experience sexual violence by an intimate partner, and up to one-third of adolescent girls report their first sexual experience as being forced” (Krug, Dahlberg, Mercy, Zwi, \& Lozano, 2002, p. 149). However, in the literature reviewed, it appears that in some parts of the world either no gender differences are found or sometimes the prevalence rate for males is higher.

For example, Al-Fayez et al. (2012) found no gender difference in the prevalence of CSA in Kuwait $(n=4,467)$, nor did Haj-Yahia and Tamish (2001) in Palestine (n = 652), and the World Health Organisation (WHO, 2005) in Lebanon ( $n=5,115$; cited in Usta \& Farver, 2010, p. 366), all of who used rigorous quantitative methodologies with large samples. However, Usta and Farver (2010) argue that the findings could reflect “a pattern of underreporting by Arab girls” (p. 365-366). In addition to issues related to "shame and duty to family” (Back et al., 2003, p. 1270) as well as fear of reprisal including death in the case of honour killings for females (Haj-Yahia \& Tamish, 2001; Shalhoub-Kevorkian, 2000; Singh, 2009; Wang \& Heppner, 2011), boys in Middle East populations are socialised to be expressive and dominant, whereas girls are expected to be submissive and accept situations they cannot change” (Usta \& Farver, 2010, p. 365-366).

Madu and Peltzer (2000) report a similar finding in South Africa. They say, "the prevalence rate among their male participants (60\%) was much higher than that reported of males by Collings (1991) (28.9\%) and higher 
than their female subjects (53.2\%), which is contrary to popular expectations and other reported findings. It may mean that the male participants felt freer or were more open in reporting their childhood sexual experiences than the females, (because) in the province (just as it is in many other Black African societies), male children are culturally encouraged to be outspoken and assertive, while female children are encouraged to be reserved and appear innocent” (p. 265).

Based on a literature review of CSA in Latin America, Thornton and Veenema (2015) found studies that report higher prevalence rates for males in Mexico and Brazil. These authors argue that "these data stand in sharp contrast to the prevailing theory that females are victimised up to four times as often as males ... (and) may indicate that previous methods of studying child sexual abuse have not been adequately designed to identify males who had been sexually abused” (p. 438-439). Chen, Dunne, and Han (2004), who have conducted extensive studies on the prevalence of CSA in China, also say that "the robust female to male gender ratio found in most studies in Western populations may not be generalisable across cultures” (p. 1172).

When attempting to unpack what is genuine and what is apparent in regards to prevalence rates among males and females, there is also the issue that males can under-report their abuse for a range of reasons, contributing to wide gaps in statistical data. For example, Thornton and Veenema (2015) say that "in Latin America, machismo attitudes make reporting victimisation difficult for young males ... (They) set a social expectation for boys and young men to be strong and resilient, (so) reporting a history of sexual abuse may be construed as an admission of weakness” (p. 439-440). Other authors, in a range of diverse communities, also note fear of being seen as weak as a barrier to disclosure among male victims/survivors (Fattah \& Kabir, 2013; Haj-Yahia \& Tamish, 2001; Lev-Wiesel \& Amir, 2005; Stoltenborgh et al., 2011).

Male victims may also fear being regarded as homosexual (Stoltenborgh et al., 2011) or feminine (Thornton \& Veenema, 2015). Gibson, Emeka, and Walters (2007) report, for example, that “male-on-male child exploitation is far more likely to be met with mob violence in Jamaica (being a very homosexual intolerant society). (Thus), male juvenile victimisation is given less attention since there is no law against the victimisation of males by males or males by females or females by females ... (and) females (become) the only legal victims of child sexual abuse” (p. 115).

Male victims “may (also) not view their sexual experiences with older women as sexual abuse because of sex stereotypes” (Stoltenborgh et al., 2011, p. 89). As Fattah and Kabir (2013) say, “sexual abuse perpetrated by females may not be perceived as abuse because women are stereotyped as caregivers and are allowed to have 
more intimate contact with children. Hence, it can be difficult, especially for younger children, to recognise if he or she is being sexually abused by a female caretaker” (p. 910). Pasura et al. (2012) similarly says of Caribbean countries, "if a boy is abused by a woman, gendered norms make it very difficult for this type of abuse to be acknowledged. Social pressures make it more likely that this will be reframed as the boy's 'education', ‘initiation’, or his ‘good luck’ regardless of any damaging effects” (p. 207).

Finally, male victims may fear they will not be believed (Lam, 2014). Consistent with this, Raissian, Dierkhising, Geiger, and Schelbe (2014) conducted a nationally representative case file review across 46 states in the US and found that "if a female adolescent's (case file) alleged sexual abuse, that report was twice as likely to generate child protection system involvement compared to a male adolescent's report alleging sexual abuse, raising (serious) concerns regarding the handling of sexual abuse reports among male adolescents” (p. 11).

It is also the case that "male victims who disclose their child sexual abuse experiences tend to do so later than female victims” (Stoltenborgh et al., 2011, p. 89). According to O’Leary and Barber (2008), “on average, it would take most male victims more than 10 years before they start to discuss their child sexual abuse experiences. For women, the average period is much shorter, which might contribute to higher prevalence rates for girls than for boys, and higher prevalence in adult male samples than child male samples, which is not the case for females” (cited in Stoltenborgh et al., 2011, p. 89). Thornton and Veenema (2015) also report that "child sexual abuse is reported less often with increasing age of males, while it increases with age in females" (p. 438).

Overall, prevalence data for males and females needs to be read with caution. "Gender differences may be due to either higher occurrence of child sexual abuse among girls, to boys’ more reluctant attitude toward disclosing” (Stoltenborgh et al., 2011, p. 89), to girls’ more reluctant attitude toward disclosing, or all of the above. Importantly, Thornton and Veenema (2015) do say, "future research endeavours should address males as victims because they are frequently ignored in the literature” (p. 440). Indeed, Chen and Chen (2005) report that "parents (in China) were more likely to communicate CSA prevention knowledge to their daughters ... (because so many), $21.3 \%$ of respondents, did not believe that boys can also be sexually abused” (p. 546). In short, preventative education carries an onus to protect all children regardless of their gender.

\subsubsection{Perpetrators}


Finkelhor, Hotaling, Lewis, and Smith (1990) found that "girls were more likely to be victimised by someone who was either an immediate or extended family member, while boys were more likely to be victimised by a stranger” (cited in Choi et al., 2015, p. 82). Specifically, “about 50\% of perpetrators against girls and 20\% against boys are family members” (Finkelhor, 1994, cited in Usta \& Farver, 2010, p. 366). Given that females are more likely to be abused than males (assuming methods for detection have so far been adequate), and given that females are more likely to be abused by someone in their family, this helps explain why the perpetrator in most research is known to the victim. Studies worldwide, e.g. Korea (Ko \& Koh, 2007), Zimbabwe (Gwirayi, 2013), Papua New Guinea (Lewis, 2012), Kuwait (Al-Fayez et al., 2012), and Latin America (Thornton \& Veenema, 2015), indicate that the most common types of perpetrators are fathers, mothers, step-fathers, mother's de factos, uncles, brothers, cousins, peers, neighbours, teachers, acquaintances, and domestic servants. Importantly, some studies have found that the number of abuse cases perpetrated by strangers was either very large or larger than those perpetrated by those known to the victim. For example, in a cross-sectional quantitative study with a large sample of 652 Palestinian undergraduate students, Haj-Yahia and Tamish (2001) found that a stranger (47\%) or distant relative (36\%), rather than a family member (9\%), had perpetrated CSA since early childhood (cited in Usta \& Farver, 2010, p. 366). In a retrospective case review of 38 consecutive cases of CSA seen at a child guidance clinic in Singapore, Yiming and Fung (2003) also report that "strangers (44.7\%) formed a large proportion of perpetrators” (p. 262). It is asserted that due to cultural issues of shame and fear in collectivist cultures (e.g. Back et al., 2003; Chan et al., 2011; Chen et al., 2004; Futa, Hsu, \& Hansen, 2001; Gilligan \& Akhtar, 2005; Haj-Yahia \& Tamish, 2001; Lewis, 2012; Li et al., 2012; Sil \& Soo, 2008; Singh, 2009), reporting extra-familial abuse may be higher in some countries because it is 'safer', leading to under-reporting of abuse perpetrated by familiar others.

This assertion may also help explain the mixed results found in Asian samples. For example, “Rhee et al. (2008) stated that most sexual abuses in Asian cultures were perpetrated by the father or siblings of the victim” (cited in Choi et al., 2015, p. 81). This is consistent with "Rao et al. (1992) who found that most Asian-American child sexual abuse survivors were assaulted by an intrafamilial perpetrator” (cited in Back et al., 2003, p. 1270), and suggests that “a clear perpetrator profile emerges” (Kenny \& McEachern, 2000, p. 917) in these groups. However, in direct contradiction, “Ima and Hohm (1991) found that Asian American families’ involvement in inflicting sexual violence against their own kin is extremely low (4.9\%)” (cited in Choi et al., 2015, p. 81-82). As Choi et al. (2015) put it, “caretakers are unlikely to report sexual abuse in Asian cultures and even less likely 
to report sexual abuse perpetrated by a family member in order to spare embarrassment and loss of face within the community” (p. 81).

In short, there are variations between studies. However, overall the data suggests that the most common types of perpetrators are those known to the victim.

\subsubsection{Culturally tailored school-based prevention programs}

While universal programs can be useful in multicultural countries like Australia, they risk falsely homogenising the needs of all victims/survivors because it falls within a 'one-size fits-all' approach. Authors in the field do call for programs that are 'culturally tailored’ (e.g. Baker et al., 2013; Fanslow, Robinson, Crengle, \& Perese, 2007; Krahe \& Knappert, 2009; Gilligan \& Akhtar, 2006; Gilligan \& Akhtar, 2005). However, as stated earlier, such programs would need to be delivered in ways that neither exclude the minority nor mainstream, and this is seen to be a significant practice challenge. One way to reconcile the issue is to incorporate the elements of culturally tailored programs that make them culturally sensitive into universal programs, so that the benefits of universal programs are preserved while still delivering a program that is elastic and responsive to the diverse milieu of its participants.

For example, one aspect of cultural sensitivity seen as critical and which could be incorporated into universal programs, is the need to take into account that children originating from collectivist cultures are raised to have utmost deference for their elders. This directly goes against learnings in a prevention program to assertively say “no” to an adult that makes a child uncomfortable (Baker et al., 2013; Daigneault, Hebert, McDuff, \& Frappier, 2012). Thus, culturally appropriate strategies would need to be developed and included in universal programs to acknowledge the cultural appropriateness of respect for elders while at the same time emphasising that no culture sanctions CSA. While this program element would be meeting a need for cultural sensitivity, it would still have cross-cultural benefits to all participating children because 'individualistic’ cultures like Australia are not absent of such collectivist characteristics (as described earlier under 'Theoretical framework'); that is, this program element is relevant to ethnic minorities in degree rather than in type.

Another critical element of cultural sensitivity that can be incorporated into universal programs is the need to meet language barriers for minority children, if applicable, through the provision of bilingual staff or interpreters (Kenny, 2010). To address the practical issue that the use of interpreters can substantially increase the length of program delivery, several concurrent sessions could be held across the school: one in English and several others 
delivered in the main languages spoken within the school. This structure is offered here as possibly effective because it aims to ensure that all children are and believe they are receiving the same universal program (and thus its associated and aforementioned benefits), while still being tailored to the specific school's 'ethnic profile’.

It is the third and final element of culturally tailored programs, however, that is seen to be critical for cultural sensitivity but not necessarily (or even ethically) able to be incorporated into universal programs, suggesting that a separate program for ethnic minority children may also be warranted. It is known in the literature that one barrier to disclosure of CSA among minority victims/survivors is racism, in the form of fear of stigmatising their whole community, and this barrier is unique to this group (Bernard, 2002; Fontes \& Plummer, 2010; Wilson, 1993; Wilson, 1994). As Barker-Collo, Read, and Cowie (2012) put it, "if one is a member of a minority or disenfranchised cultural group, then one may have the added burden of the abuse potentially being perceived as a 'cultural' issue” (p. 438-439). Culturally tailored programs offer the space required to address this key barrier, by allowing discussion of any racism or discrimination that may be impacting on the ethnic minority victims' traumatisation experience.

In short, the literature calls for culturally tailored programs to ensure they are responsive and sensitive to the cultural needs of its participants. However, it is argued here that in Western multicultural countries like Australia, the risk of delivering 'culturally tailored' programs - which bring focus to ethnic minorities and thus can further racism and negative stereotyping among children already vulnerable from the trauma of CSA - is not outweighed by the need for cultural sensitivity. Further research is required to identify when 'culturally tailored' program elements can be incorporated into universal program (e.g. being sensitive to collectivism, and providing interpreters) and when they cannot (e.g. discussing racism as a barrier to disclosure). It may be that for culturally tailored programs to meet the need for cultural sensitivity and responsiveness without the risk of heightening racism as a barrier to disclosure that they be delivered outside of the school system and within specific ethnic communities.

\subsubsection{Designing and evaluating school-based programs}

Daigneault et al (2012) assert that the "most effective (CSA prevention) programs are those of longer duration (four sessions or more), those that involve repetition of important ideas and concepts, those that demand active participation from children with multiple occasions to practice new skills and abilities, and those that are based 
on concrete concepts rather than abstract notions” (p. 523). Thus, school-based prevention programs would need to ensure they contain these critical components.

It may also be the case that males in particular need education on myths about CSA. Example items extracted from the seminal scale designed by Collings (1997) on 'CSA myths' include: sexual contact between an adult and a child which is wanted by the child and which is physically pleasurable for the child cannot really be described as abuse; children who act in a seductive manner must be seen as being at least partly to blame if an adult responds to them in a sexual way; and children who do not report ongoing sexual abuse must want the sexual contact to continue. The main purpose of such myths is to shift culpability for the crime from the perpetrator to the victim. In the context that most victims are female (assuming methods of detection have so far been adequate), such myths also then protect and preserve patriarchal structures (Sawrikar \& Katz, 2017). As Gibson et al. (2007) put it, they make “females somehow complicit in victimisations” (p. 111). Indeed, Collings et al. (2009) report that "men have been found to be more victim-blaming than women, with attributions of blame decreasing as a function of more education” (p. 9).

Teachers would also need training. For example, in the context of Jamaica, Samms and Cholewa (2014) say, "in spite of economic challenges, it is important for school administrators to collaborate and conduct professional development workshops that provide teachers with basic knowledge and training on how to identify and refer a child who has been sexually abused so they may receive appropriate care. Workshops should also focus on facilitating open communication between teachers and students ... (to help) dissolve the stigma attached to sharing information on sexual abuse to persons outside the family” (p. 122-123). These learnings can capitalise on a 'train-the-trainer model' too (Baker et al., 2013). "In Zimbabwe, child abuse is currently taught as a topic to teachers, but there is call for it to be an examinable subject” (Gwirayi \& Shumba, 2008, p. 285).

One of the most significant outcomes of school-based prevention programs is that they may increase disclosures of "prior or current abuse, thus stopping ongoing abuse and helping children access support and services sooner than they might otherwise” (Baker et al., 2013, p. 168). They may also be associated with a decreased likelihood that children will blame themselves after the abuse (Finkelhor, 2007, cited in Baker et al., 2013). These are all critical outcomes that would be evidence of the success of these programs. This is especially important to consider given that while "school-based programs have the potential to increase children's knowledge and skills in ways that may protect them from child sexual abuse, it has not yet been demonstrated that these are 
successfully transmitted to real-life situations ... (that actually prevent abuse) or limit repeat victimisation” (Fanslow et al., 2007, p. 944).

"Critics have (also) raised concerns over the usefulness of preventative programs given hypothesised potential negative effects such as increased anxiety, fear of positive or benign touch, and effects on later sexual development ... (However), several studies have found that these concerns were either unfounded or minor" (Baker et al., 2013, p. 168). For example, studies have found "some evidence of increased anxiety in a small number of children after a sexual abuse prevention program, but coupled with high satisfaction with the program, (and) Topping and Barron (2009) report that over a third of the studies they reviewed found evidence of emotional gains, including greater sense of efficacy in using self-protective skills, increased self-esteem, and less social anxiety” (cited in Baker et al., 2013, p. 168).

Thus, education does play a key role in prevention. As Gibson et al. (2007) say of the context in Jamaica, but really with learnings that are transferable to all parts of the world:

Students should be educated in their schools about sex, sexual abuse, and personal safety. Educational efforts should be age appropriate and evaluated at least once annually for effectiveness. Such an effort will need to be gradual, persistent, and firm because the cultural norms of Jamaica are stark against parents discussing sex with their children. Sanctions for the sexual abuse of children need to be applied unapologetically. An aggressive media campaign should be launched that makes it clear certain behaviors are totally unacceptable to transfer stigma away from blaming victims and on to offenders. When a minor summons the courage to report sexual victimisation, the cost should not be less than had the child remained silent (p. 117-118).

Moreover, the evaluation of prevention programs would require (culturally) appropriate indicators of their effectiveness. For ethnic minority communities, specifically, cultural pressure to protect the family name may delay or prohibit disclosure of abuse and therefore professional help-seeking, which could then be falsely used as evidence that educational/preventative programs are not working for them.

\subsubsection{Barriers to participation in school-based prevention programs}

So far, the literature has established that school-based programs are common and useful for educating children with the aim of preventing CSA. While it may not lead to many disclosures or help-seeking among ethnic minority communities due to cultural pressure to protect the family name, self-protective education and 
education about the threat of CSA are still critical. Knowledge that all children are equally protected by the (Australian) government is also critical. However, this vital education may miss children from ethnic minority communities if parents do not give permission for their children to take part in such programs, which in turn may occur because of the widespread taboo of not discussing any matters to do with sex including abuse. This taboo has been noted in several diverse communities, such as in Puerto Rico (Kenny \& McEachern, 2000), China (Chen et al., 2007; Chien, 2013), Southeast Asian communities (Futa et al., 2001), Israel (Elbedour, AbuBader, Onwuegbuzie, Abu-Rabia, \& El-Aassam, 2006; Lev-Wiesel \& Amir, 2005), India (Karthiga \& Ravikumar, 2014), Taiwan (Wang \& Heppner, 2011), Africa (Masehela \& Pillay, 2014), among Dutch Antillean/Surinamese minorities (Okur et al., 2016), in Arab American communities (Haboush \& Alyan, 2013), in South Asian Muslim society in the UK (Chand \& Thoburn, 2006), and among CALD women in Australia (Allimant \& Ostapiej-Piatkowski, 2011).

Chen et al. (2007) report that "nearly all parents $(97.7 \% ; n=652)$ agreed that child sexual abuse prevention programs should be offered in schools, and 95.5\% were willing to let their own children learn about child sexual abuse in school ... (but) despite these positive attitudes, many parents (also) expressed unease about it; nearly half (46.8\%) said they were worried that child sexual abuse prevention education might lead their children to know “too much about sex”” (p. 751).

In a related study conducted by Chen and Chen (2005) with 385 parents of Grade 3 pupils in China, the authors also assert that "a possible reason why so many parents had not explored key ideas (of prevention) with their children could be due to the fact that parents had not received such education themselves. Only $7.9 \%$ of them had been told about how to prevent child sexual abuse by their guardians and only $6.8 \%$ of them reported that their teachers had talked about child sexual abuse prevention during their school years” (p. 546). This finding also highlights the relevance of this cultural barrier across generations.

Karthiga and Ravikumar (2014) conducted a study $(n=100)$ to explore the cultural and patriarchal relevance of CSA in the conservative town of Madurai, India. Based on their findings, they similarly say, "the reasons why (parents) fail to educate their children on child sexual abuse include (a) fear that if prior warning is given, children will see abuse everywhere; (b) not wanting to disrupt the innocence of their children; (c) fearing the child might accuse them of sexual abuse; (d) fearing the child would become more curious about sexual issues; and (e) believing that part of a parent's protective role is to maintain their child's ignorance about the social environment” (p. 735-736). 
However, "when sexual matters are not discussed in any organised form and children are left to rely on information from peers, it is likely that reporting abusive sexual behavior becomes difficult” (Kisanga Nystrom, Hogan, \& Emmelin, 2011, p. 199). Thus, parents may have reticence regarding their children taking part in prevention programs; a cultural barrier that would need to be addressed. As Chen and Chen (2005) put it, "programmes will meet resistance because of the sensitive nature of the topic, (so) there must be official support for schools and parents to cooperate together in developing a child sexual abuse prevention curriculum that will meet the needs of their children and address parents’ sensitivities” (p. 546).

\subsection{RQ 2 - What role can service agencies play to improve the prevention of CSA in ethnic minority communities?}

As stated earlier, one theme explored in the larger review was that of national service provision. This was conducted by scoping the websites of 66 service organisations in Australia that deliver treatment services to victims/survivors of CSA for the diversity of their visual images ('promotional inclusiveness'; Allimant \& Ostapiej-Piatkowski, 2011; Fontes, 2005; Weeks, 2002) and information provided about/specific to CALD clients. Two of these organisations were ‘ethno-specific' (Jewish/Muslim5 ), two were 'multicultural' (catering to all ethnic minority backgrounds ${ }^{6}$ ), and the remaining 62 were 'mainstream' organisations available to all victims/survivors regardless of their cultural background and therefore not culturally tailored. ${ }^{7}$

Overall, it appeared that national organisations do not really address cultural diversity deeply in their practice; only 7 of the 62 mainstream organisations (11\%) had visual images that included people of CALD background, 29 (47\%) provided a link to other CALD-focused organisations rather than addressing cultural issues explicitly on their own website compared to 7 (11\%) who did to a greater or lesser extent ${ }^{8}$, and 7 (11\%) offered their website in multiple languages, an interpreter for counselling, and/or translated information documents. This

\footnotetext{
${ }^{5}$ www.tzedek.org.au; http://ausmuslimwomenscentre.org.au/

${ }^{6}$ http://www.iwss.org.au/; http://www.dhi.health.nsw.gov.au/Transcultural-Mental-Health-Centre/TransculturalMental-Health-Centre-Home/default.aspx

${ }^{7}$ These URLs have not been provided here due to the high number. However, some are identified under footnote 6 .

${ }^{8}$ www.1800respect.org.au; www.crcc.org.au; www.catholiccare.org; www.livingwell.org.au; www.rapedvservices.org.au; www.samsn.org.au; www.kemh.health.wa.gov.au/services/sarc/;
} 
suggests that a much larger role could be played by service organisations in the prevention of CSA among ethnic minority communities.

\subsubsection{Co-delivering school-based programs with service organisations}

One suggestion for improving the prevention of CSA is for schools to partner with local service organisations that deliver frontline treatment to victims. Such a partnership could serve two main goals. First, practitioners provide a 'face' to children in need of treatment and can inform all children of their role and availability in the local community. In the Australian context, where service providers are mandatory reporters, they would also be able to explain that they cannot work with the child until they have also disclosed to their family and passed through statutory child protection assessment that could invite a system response deemed or feared as punitive within families, but that both child and family therapy are on offer to them.

Secondly, service organisations act as a 'safe broker' in cases where CSA has been perpetrated by teachers and/or exacerbated by an unprotective response from the school; 'institutional CSA'. As an example, Masehela and Pillay (2014) report that "of particular concern (in South Africa) is the continuing sexual exploitation of school children by teachers ... Child victims are afraid that reporting would lead to retribution by the teacher (falling grades, harsh punishment, public humiliation), punishment by parents (traditional values forcing children not to discuss sexual matters), inability to survive due to loss of income (termination of child maintenance payments), and alienation from the community and its (emotional and social) resources” (p. 22, 29). Importantly, this type of institutional CSA is not exclusive to non-Western countries as reports continue to be presented to the Royal Commission into Institutional Responses to Child Sexual Abuse (2013-2017) ${ }^{9}$ emerging from Australian schools.

\subsubsection{Secondary prevention: The role of health professionals for identification}

Another suggestion for improving the prevention of CSA is for frontline service providers to train other health care workers, which the literature briefly discusses. The ability to identify a sexually abused child falls under 'secondary prevention’ (Ige \& Fawole, 2011) in that it leads to early recognition, treatment, and prevention of further abuse. Thus, "early intervention is recommended to reduce the risk of long-term negative outcomes" (Mathews et al., 2013, p. 640). As an example, Ko and Koh (2007) say, nurses (in Korea) “consistently have

\footnotetext{
${ }^{9}$ http://childabuseroyalcommission.gov.au/
} 
early and direct contact with abusive families and their children (so) are in a strategic position for early assessment, treatment, and prevention. To fulfil this position responsibility, it is crucial they be capable of recognising child sexual abuse and strengthen their skills to intervene in suspected cases” (p. 1166).

Arguably, the most relevant myth about CSA (Collings, 1997) in the health care context is that it is associated with physical injuries. The implication is that children without physical injuries are less likely to be identified.

Zeitler et al. (2006) reports that "young ethnic minority women (in the US) who have experienced child sexual abuse or violence in an intimate relationship are less likely to support screening by a health care provider. (Despite that) reaching these women will be a challenge for providers” (p. 119.e6), efforts to screen and probe for a possible history of CSA are still critical for identification and treatment.

This is particularly important because reticence to screen and probe has also been noted by health care professionals (Yehuda, Friedman, Rosenbaum, Labinsky, \& Schmeidler, 2007). As one example, Sil and Soo (2008) say, "the taboo (in Korea) associated with incest means that both victims and health professionals are reluctant to explore (it). Even when confronted by overt evidence, health professionals may be hesitant to believe that such an awful thing could take place in "such a perfect family”, and may dismiss the possibility” (p. 81).

Overall, the literature suggests that there are barriers to the early identification of CSA. Victims may not want to be screened and health care professionals may be reluctant to ask, especially in the absence of physical injuries that could act as prompts to inquire further. This has practice implications on the provision of training to health care professionals to help improve their recognition of CSA and confidence in screening and probing for a possible history, and service organisations may be able to play a part in this.

\subsubsection{Summary}

The original aim of this research question was to identify culturally appropriate strategies that service agencies could be involved in to help improve the prevention of CSA in ethnic minority communities. However, the two suggestions offered here based on themes in the reviewed literature - co-delivering school-based programs and training other health professionals - go beyond just ethnic minorities with applicability to all groups. Thus, service agencies can be involved in 'universal' (or non-culturally tailored) prevention efforts of CSA in multicultural countries like Australia, but can also tailor their specific services to better acknowledge their 
country's ethnic diversity by improving promotional inclusiveness, addressing cultural diversity explicitly, and providing language options.

\section{$4 \quad$ Discussion}

\subsection{Summary and future research}

The international literature shows that most prevention efforts are in the school system. The lack of national research means that the effectiveness (or even implementation) of universal and culturally tailored school-based programs are unknown. When national researchers do heed this call, it will be necessary to ensure culturally appropriate indicators are used. Collectivist values for the family name can delay disclosure and help-seeking among victims/survivors of CSA in ethnic minority communities. Thus, disclosure and help-seeking should not be used as evidence for the effectiveness of prevention efforts. Instead, an understanding of the importance of family reputation should be used to inform the design of school-based programs, the development of strategies to address barriers to participation, and evaluation of the importance of education about CSA.

To help develop a more whole-of-systems approach, professionals from service organisations could partner with schools to co-deliver prevention programs and provide training to other health professionals (e.g. General Practitioners [GPs], nurses, etc.). The former suggestion is particularly useful in cases where abuse has been perpetrated by teachers and/or responses to disclosure have been non-supportive by schools in the past, and the latter suggestion would help improve early intervention and thus secondary prevention. Both suggestions help mobilise the contribution of service organisations to prevention but require empirical investigation in the future for their effectiveness.

\subsection{Significance}

Overall, this review is a critical contribution to the national literature on CSA and ethnic minority communities. Australia's lack of responsiveness to its multicultural milieu in the child protection sector with a well-developed research agenda to help inform good practice has long been noted (Bromfield \& Arney, 2008; Burke \& Paxman, 2008; Cashmore, Higgins, Bromfield, \& Scott, 2006; Sawrikar, 2017). This article goes some way toward addressing this gap, by shedding light on the difficulty associated with a universal versus culturally appropriate approach to the prevention of CSA in the school and service system arenas. 


\section{References}

Al-Fayez, G. A., Ohaeri, J. U., \& Gado, O. M. (2012). Prevalence of physical, psychological, and sexual abuse among a nationwide sample of Arab high school students: Association with family characteristics, anxiety, depression, self-esteem, and quality of life. Social Psychiatry and Psychiatric Epidemiology, 47(1), 53-66.

Allimant, A., \& Ostapiej-Piatkowski, B., (2011). Studies, (2011). Supporting women from CALD backgrounds who are victims/survivors of sexual violence: challenges and opportunities for practitioners. Australian Centre for the Study of Sexual Assault (ACSSA) Wrap, No. 9, 1-16, Melbourne: Australian Institute of Family Studies.

Australian Bureau of Statistics (ABS, 2016). Catalogue 2071.0: Census of Population and Housing.

http://www.abs.gov.au/ausstats/abs@.nsf/Lookup/by\%20Subject/2071.0 2016 Main\%20Features Cultural\%20 Diversity\%20Article 20?OpenDocument\&ref=story

Australian Bureau of Statistics (ABS, 2012). Catalogue 1301.0: Year Book of Australia.

http://www.abs.gov.au/ausstats/abs@.nsf/Lookup/1301.0Main+Features592012

Back, S. E., Jackson, J. L., Fitzgerald, M., Shaffer, A., Salstrom, S., \& Osman, M. M. (2003). Child sexual and physical abuse among college students in Singapore and the United States. Child Abuse and Neglect, 27(11), $1259-1275$.

Baker, C. K., Gleason, K., Naai, R., Mitchell, J., \& Trecker, C. (2013). Increasing knowledge of sexual abuse: A study with elementary school children in Hawai'i. Research on Social Work Practice, 23(2), 167-178.

Barker-Collo, S., Read, J., \& Cowie, S. (2012). Coping strategies in female survivors of childhood sexual abuse from two Canadian and two New Zealand cultural groups. Journal of Trauma and Dissociation, 13(4), 435-447.

Bernard, C. (2002). Parental maltreatment of black children in the context of societal racism. Child and Family Social Work, 7(4), 239-51.

Berry, J. W. (1980). Acculturation as varieties of adaptation. In A. M. Padilla (Ed.), Acculturation: Theory, models, and some new findings. Boulder, CO: Westview.

Bond, M. H. (2002). Reclaiming the individual from Hofstede’s ecological analysis-A 20-year odyssey: Comment on Oyserman et al. (2002). Psychological Bulletin, 128, 73-77. 
Bromfield, L. \& Arney, F. (2008). Developing a road map for research: Identifying priorities for a national child protection research agenda: Issues paper. Australian Institute of Family Studies, No 28.

Burke, S. \& Paxman, M. (2008). Children and young people from Non-English speaking backgrounds in Out of Home Care in NSW. Sydney: NSW Department of Community Services.

Capri, C. (2013). Madness and defence: Interventions with sexually abused children in a low-income South African community. European Journal of Psychotherapy and Counselling, 15(1), 32-52.

Cashmore, J., Higgins, D. J., Bromfield, L., \& Scott, D. A. (2006). Recent Australian child protection and out of home care research: What's been done and what needs to be done? Children Australia, 31(2), 4-11.

Chan, Y. C., Lam, G. L. T., \& Shae, W. C. (2011). Children's views on child abuse and neglect: Findings from an exploratory study with Chinese children in Hong Kong. Child Abuse and Neglect, 35(3), 162-172.

Chand, A., \& Thoburn, J. (2006). Research review: Child protection referrals and minority ethnic children and families. Child and Family Social Work, 11(4), 368-377.

Chen, J. Q., \& Chen, D. G. (2005). Awareness of child sexual abuse prevention education among parents of Grade 3 elementary school pupils in Fuxin City, China. Health Education Research, 20(5), 540-547.

Chen, J., Dunne, M. P., \& Han, P. (2007). Prevention of child sexual abuse in China: Knowledge, attitudes, and communication practices of parents of elementary school children. Child Abuse and Neglect, 31(7), 747-755.

Chen, J., Dunne, M. P., \& Han, P. (2004). Child sexual abuse in China: A study of adolescents in four provinces. Child Abuse and Neglect, 28(11), 1171-1186.

Chien, M. H. (2013). Identifying key components of an internet information system for Chinese survivors of childhood sexual abuse. Journal of Ethnic \& Cultural Diversity in Social Work, 22(3-4), 256-270.

Choi, K. S., Choo, K., Choi, J., \& Woo, Y. (2015). Understanding the dynamics of the victim-perpetrator relationship in child sexual abuse: An examination of the child sex abuse victimization data in South Korea. Asian Journal of Criminology, 10(1), 79-97.

Collings, S. J., Lindblom, L., Madu, S. N., \& Park, M. S. (2009). The cross-cultural validity of the child sexual abuse myth scale: A preliminary investigation. Journal of Psychology in Africa, 19(1), 9-18. 
Collings, S. J., Griffiths, S., \& Kumalo, M. (2005). Patterns of disclosure in child sexual abuse. South African Journal of Psychology, 35(2), 270-285.

Collings, S, J. (1997). Development, reliability, and validity of the child sexual abuse myth scale. Journal of Interpersonal Violence, 12(5), 665-674.

Daigneault, I., Hebert, M., McDuff, P., \& Frappier, J.-Y. (2012). Evaluation of a aexual abuse prevention workshop in a multicultural, impoverished urban area. Journal of Child Sexual Abuse, 21(5), 521-542.

Elbedour, S., Abu-Bader, S., Onwuegbuzie, A. J., Abu-Rabia, A., \& El-Aassam, S. (2006). The scope of sexual, physical, and psychological abuse in a Bedouin-Arab community of female adolescents: The interplay of racism, urbanization, polygamy, family honor, and the social marginalization of women. Child Abuse and Neglect, 30(3), 215-229.

Elliot, J. M., Tong, C. K., \& Tan, P. M. E. H. (1997). Attitudes of the Singapore public to actions suggesting child abuse. Child Abuse and Neglect, 21, 445-464.

Fanslow, J. L., Robinson, E. M., Crengle, S., \& Perese, L. (2007). Prevalence of child sexual abuse reported by a cross-sectional sample of New Zealand women. Child Abuse and Neglect, 31(9), 935-945.

Fattah, K. N., \& Kabir, Z. N. (2013). No place is safe: Sexual abuse of children in rural Bangladesh. Journal of Child Sexual Abuse, 22(8), 901-914.

Finkelhor, D. (2007). Prevention of sexual abuse through educational programs directed toward children. Pediatrics, 120, 640-645.

Finkelhor, D. (1994). Current information on the scope and nature of child sexual abuse. Future Child, 4, 31-53.

Finkelhor, D., Hotaling, G., Lewis, I., \& Smith, C. (1990). Sexual abuse in a national survey of adult men and women: prevalence, characteristics, and risk factors. Child Abuse and Neglect, 14, 19-28.

Finkelhor, D. \& Browne, A. (1985). The traumatic impact of child sexual abuse: A conceptualisation. American Journal of Orthopsychiatry, 55, 530-541.

Fontes, L. A., \& Plummer, C. (2010). Cultural issues in disclosures of child sexual abuse. Journal of Child Sexual Abuse, 19(5), 491-518. 
Fontes, L. A. (2005). Child abuse and culture: Working with diverse families. New York: Guilford Press.

Fontes, L. (1993). Considering culture and oppression. Journal of Feminist Family Therapy, 5(1), 25-54.

Futa, K. T., Hsu, E., \& Hansen, D. J. (2001). Child sexual abuse in Asian American families: An examination of cultural factors that influence prevalence, identification, and treatment. Clinical Psychology: Science and Practice, 8(2), 189-209.

Gibson, C., Emeka, T. Q., \& Walters, N. (2007). Sexual abuse of minors in Jamaica: Understanding predator, prey, and citizenry. Journal of Ethnicity in Criminal Justice, 5(2-3), 109-122.

Gilligan, P., \& Akhtar, S. (2006). Cultural barriers to the disclosure of child sexual abuse in Asian communities: Listening to what women say. British Journal of Social Work, 36(8), 1361-1377.

Gilligan, P., \& Akhtar, S. (2005). Child sexual abuse among Asian communities: Developing materials to raise awareness in Bradford. Practice (UK), 17(4), 267-284.

Gwirayi, P. (2013). The prevalence of child sexual abuse among secondary school pupils in Gweru, Zimbabwe. Journal of Sexual Aggression, 19(3), 253-263.

Gwirayi, P., \& Shumba, A. (2008). Childhood sexual abuse experiences of female student teachers in Zimbabwe. Journal of Psychology in Africa, 18(2), 283-286.

Haboush, K. L., \& Alyan, H. (2013). “Who can you tell?” Features of Arab culture that influence conceptualization and treatment of childhood sexual abuse. Journal of Child Sexual Abuse, 22(5), 499-518.

Haj-Yahia, M. M., \& Tamish, S. (2001). The rates of child sexual abuse and its psychological consequences as revealed by a study among Palestinian university students. Child Abuse and Neglect, 25(10), 1303-1327.

Hofstede (2001): http://www.clearlycultural.com/geert-hofstede-cultural-dimensions/individualism/

Hofstede, G. H. (1980). Culture’s consequences: International differences in work-related values. Beverly Hills, Calif: Sage Publications.

Ige, O. K., \& Fawole, O. I. (2011). Preventing child sexual abuse: Parents’ perceptions and practices in urban Nigeria. Journal of Child Sexual Abuse, 20(6), 695-707. 
Ima, K., \& Hohm, C. F. (1991). Child maltreatment among Asian and Pacific Islander refugees and immigrants: the San Diego case. Journal of Interpersonal Violence, 6(3), 267-285.

Jewkes, R. K., Dunkle, K., Nduna, M., Jama, P. N., \& Puren, A. (2010). Associations between childhood adversity and depression, substance abuse and HIV and HSV2 incident infections in rural South African youth. Child Abuse and Neglect, 34(11), 833-841.

Ji, K., Finkelhor, D., \& Dunne, M. (2013). Child sexual abuse in China: A meta-analysis of 27 studies. Child Abuse and Neglect, 37(9), 613-622.

Karthiga, R. K. J., \& Ravikumar, R. (2014). Child sexual abuse in Madurai, India: A literary review and empirical study. Journal of Child Sexual Abuse, 23(6), 727-744.

Kenny, M. C. (2010). Child sexual abuse education with ethnically diverse families: A preliminary analysis. Children and Youth Services Review, 32(7), 981-989.

Kenny, M. C., \& McEachern, A. G. (2000). Racial, ethnic, and cultural factors of childhood sexual abuse: A selected review of the literature. Clinical Psychology Review, 20(7), 905-922.

Kenny, M. C., \& Wurtele, S. K. (2012). Preventing childhood sexual abuse: An ecological approach. Journal of Child Sexual Abuse, 21(4), 361-367.

Kisanga, F., Nystrom, L., Hogan, N., \& Emmelin, M. (2011). Child sexual abuse: Community concerns in urban Tanzania. Journal of Child Sexual Abuse, 20(2), 196-217.

Ko, C., \& Koh, C. K. (2007). The influence of abuse situation and respondent background characteristics on Korean nurses’ perceptions of child sexual abuse: A fractional factorial design. International Journal of Nursing Studies, 44(7), 1165-1176.

Krahe, B., \& Knappert, L. (2009). A group-randomized evaluation of a theatre-based sexual abuse prevention programme for primary school children in Germany. Journal of Community \& Applied Social Psychology, 19(4), 321-329.

Krug, E. G., Dahlberg, L. L., Mercy, J. A., Zwi, A. B., Lozano, R. (2002). World Report on Violence and Health. Geneva: World Health Organisation. 
Lam, K. Y. I. (2014). Factors associated with adolescents’ disclosure of sexual abuse experiences in Hong Kong. Journal of Child Sexual Abuse, 23(7), 768-791.

Lev-Wiesel, R., \& Amir, M. (2005). Holocaust child survivors and child sexual abuse. Journal of Child Sexual Abuse, 14(2), 69-83.

Lewis, I. R. (2012). At risk: The relationship between experiences of child sexual abuse and women’s HIV status in Papua New Guinea. Journal of Child Sexual Abuse, 21(3), 273-294.

Li, N., Ahmed, S., \& Zabin, L. S. (2012). Association between childhood sexual abuse and adverse psychological outcomes among youth in Taipei. Journal of Adolescent Health, 50(3, Suppl), S45-S51.

Madu, S. N., \& Peltzer, K. (2000). Risk factors and child sexual abuse among secondary school students in the Northern Province (South Africa). Child Abuse and Neglect, 24(2), 259-268.

Mansbach-Kleinfeld, I., Ifrah, A., Apter, A., \& Farbstein, I. (2015). Child sexual abuse as reported by Israeli adolescents: Social and health related correlates. Child Abuse and Neglect, 40, 68-80.

Masehela, B., \& Pillay, V. (2014). Shrouds of silence: A case study of sexual abuse in schools in the Limpopo Province in South Africa. Perspectives in Education, 32(3), 22-35.

Mathews, B., Walsh, K., Dunne, M., Katz, I., Arney, F., Higgins, D.,... \& Bates, S. (2016). Scoping study for research into the prevalence of child abuse in Australia: report to the Royal Commission into Institutional Responses to Child Sexual Abuse. Sydney: Social Policy Research Centre, UNSW Australia in partnership with Australian Institute of Family Studies, Queensland University of Technology, and the Australian Centre for Child Protection (University of South Australia).

Mathews, S., Abrahams, N., \& Jewkes, R. (2013). Exploring mental health adjustment of children post sexual assault in South Africa. Journal of Child Sexual Abuse, 22(6), 639-657.

Moher, D., Liberati, A., Tetzlaff, J., Altman, D. G., \& The PRISMA Group. (2009). Preferred Reporting Items for Systematic Reviews and Meta-Analyses: The PRISMA Statement. PLoS Med, 6(7), e1000097.

O’Hagan. (1999). Culture, cultural identity, and cultural sensitivity in child and family social work. Child and Family Social Work, 4(4), 269-281. 
Okur, P., van der Knaap, L. M., \& Bogaerts, S. (2016). Ethnic differences in help-seeking behaviour following child sexual abuse: A multi-method study. Culture, Health, and Sexuality, 18(1), 99-111.

O’Leary, P. J., \& Barber, J. (2008). Gender differences in silencing following childhood sexual abuse. Journal of Child Sexual Abuse, 17(2), 133-143.

Owusu-Bempah, K., \& Howitt, D. (2000). Psychology beyond Western perspectives: London: Wiley-Blackwell.

Pasura, D., Jones, A. D., Hafner, J. A. H., Maharaj, P. E., Nathaniel-DeCaires, K., \& Johnson, E. J. (2013).

Competing meanings of childhood and the social construction of child sexual abuse in the Caribbean.

Childhood, 20(2), 200-214.

Pereda, N., Guilera, G., Forns, M., \& Gomez-Benito, J. (2009). The international epidemiology of child sexual abuse: A continuation of Finkelhor (1994). Child Abuse and Neglect, 33(6), 331-342.

Raissian, K. M., Dierkhising, C. B., Geiger, J. M., \& Schelbe, L. (2014). Child maltreatment reporting patterns and predictors of substantiation: Comparing adolescents and younger children. Child Maltreatment, 19(1), 3-16.

Rao, K., DiClemente, R. J., \& Ponton, L. E. (1992). Child sexual abuse of Asians compared with other populations. Journal of the American Academy of Child and Adolescent Psychiatry, 31, 880-886.

Rhee, S., Chang, J., Weaver, D., \& Wong, D. (2008). Child maltreatment among immigrant Chinese families: Characteristics and patterns of placement. Child Maltreatment, 13(3), 269-279.

Samms, K. M., \& Cholewa, B. E. (2014). Exploring the context of child sexual abuse in Jamaica: Addressing the deficits. Journal of Child Sexual Abuse, 23(2), 115-127.

Sawrikar, P. (2017). Working with ethnic minorities and across cultures in Western child protection systems. UK: Routledge.

Sawrikar, P. \& Katz, I. (2017). How aware of child sexual abuse (CSA) are ethnic minority communities? A literature review and suggestions for raising awareness in Australia. Children and Youth Services Review, 81, 246-260.

Sawrikar, P. \& Katz, I. (2009). How useful is the term “Culturally And Linguistically Diverse (CALD)” in the Australian social policy discourse? Refereed conference paper, Australian Social Policy Conference (ASPC). 
Sawrikar, P. \& Katz, I. (2008). Enhancing family and relationship service accessibility and delivery to culturally and linguistically diverse (CALD) families in Australia, Issues paper prepared for the Australian Family Relationships Clearinghouse (AFRC), Australian Institute of Family Studies (AIFS), Issues No. 3.

Shalhoub-Kevorkian, N. (2005). Disclosure of child abuse in conflict areas. Violence Against Women, 11(10), 1263-1291.

Shalhoub-Kevorkian, N. (2000). Blocking her exclusion: A contextually sensitive model of intervention for handling female abuse. Social Service Review, 74(4), 620-634.

Shalhoub-Kevorkian, N. (1999). The politics of disclosing female sexual abuse: a case study of Palestinian society. Child Abuse and Neglect, 23, 1275-1293.

Sil, K. H., \& Soo, K. H. (2008). Intra-familial sexual abuse (incest) among Korean adolescents. Family Relations: 21st Century Issues and Challenges (pp. 71-86).

Singh, A. A. (2009). Helping South Asian immigrant women use resilience strategies in healing from sexual abuse: A call for a culturally relevant model. Women and Therapy, 32(4), 361-376.

Stewart, S. (2005). Suicidality, interpersonal trauma and cultural diversity: A review of the literature. Australian e-Journal for the Advancement of Mental Health (AeJAMH), 4(2), 21p.

Stoltenborgh, M., van Ijzendoorn, M. H., Euser, E. M., \& Bakermans-Kranenburg, M. J. (2011). A global perspective on child sexual abuse: Meta-analysis of prevalence around the world. Child Maltreatment, 16(2), 79-101.

Taylor, S., \& Norma, C. (2013). The ties that bind: family barriers for adult women seeking to report childhood sexual assault in Australia. Women's Studies International Forum, 37, 114-124.

Thornton, C. P., \& Veenema, T. G. (2015). Children seeking refuge: A review of the escalating humanitarian crisis of child sexual abuse and HIV/AIDS in Latin America. JANAC: Journal of the Association of Nurses in AIDS Care, 26(4), 432-442.

Tishelman, A. C., \& Geffner, R. (2010). Forensic, cultural, and systems issues in child sexual abuse cases-Part 1: An introduction. Journal of Child Sexual Abuse, 19(5), 485-490. 
Topping, K. J., \& Barron, I. G. (2009). School-based child sexual abuse prevention programs: A review of effectiveness. Review of Educational Research, 79, 431-463.

Triandis, H. C. (1990). Theoretical concepts that are applicable to the analysis of ethnocentricism. In R. W. Brislin (Ed.), Applied cross-cultural psychology. New York: Sage.

Usta, J., \& Farver, J. (2010). Child sexual abuse in Lebanon during war and peace. Child: Care, Health and Development, 36(3), 361-368.

Vermeulen, T., \& Greeff, A. P. (2015). Family resilience resources in coping with child sexual abuse in South Africa. Journal of Child Sexual Abuse, 24(5), 555-571.

Walker, M. D., Hernandez, A. M., \& Davey, M. (2012). Childhood sexual abuse and adult sexual identity formation: Intersection of gender, race, and sexual orientation. American Journal of Family Therapy, 40(5), 385-398.

Wang, Y-W., \& Heppner, P. (2011). A qualitative study of childhood sexual abuse survivors in Taiwan: Toward a transactional and ecological model of coping. Journal of Counseling Psychology, 58(3), 393-409.

Weeks, W. (2002). Access and equity in services against sexual violence. Women Against Violence: An Australian Feminist Journal, 11, 22-34.

Wilson, M. (1994). Crossing the boundary: Black women survive incest. Seattle, WA: Seal Press.

Wilson, M. (1993). Crossing the boundary. London: Virago.

Yehuda, R., Friedman, M., Rosenbaurn, T. Y., Labinsky, E., \& Schmeidler, J. (2007). History of past sexual abuse in married observant Jewish women. The American Journal of Psychiatry, 164(11), 1700-1706.

Yiming, C., \& Fung, D. (2003). Child sexual abuse in Singapore with special reference to medico-legal implications: A review of 38 cases. Medicine, Science and the Law, 43(3), 260-266.

Yoshihama, M., \& Horrocks, J. (2010). Risk of intimate partner violence: Role of childhood sexual abuse and sexual initiation in women in Japan. Children and Youth Services Review, 32(1), 28-37. 
Zeitler, M. S., Paine, A. D., Breitbart, V., Rickert, V. I., Olson, C., Stevens, L... \& Davidson, L. L. (2006). Attitudes about intimate partner violence screening among an ethnically diverse sample of young women. Journal of Adolescent Health, 39(1), e1-e8.s 
Appendix A: Summary of articles obtained through PRISMA process directly addressing the theme of prevention

\begin{tabular}{|c|c|c|}
\hline AUTHORS & $\begin{array}{l}\text { COUNTRY/IES } \\
\text { STUDY CONDUCTED } \\
\text { IN }\end{array}$ & METHOD/RIGOUR \\
\hline \multicolumn{3}{|l|}{ Based in Western contexts } \\
\hline 1. $\quad$ Baker et al (2013) & Hawai’i & $\begin{array}{l}\text { Quasi-experiemental 'train the trainer' } \\
\text { evaluation }(n=80)\end{array}$ \\
\hline 2. Daigneault et al (2012) & Canada (various) & $\begin{array}{l}\text { Longitudinal quantitative workshop evaluation } \\
(\mathrm{n}=160)\end{array}$ \\
\hline 3. $\quad$ Gilligan \& Akhtar (2006) & UK (South Asians) & $\begin{array}{l}\text { Qualitative consultations on awareness-raising } \\
\text { information booklet }\end{array}$ \\
\hline 4. Gilligan \& Akhtar (2005) & UK (South Asians) & $\begin{array}{l}\text { Mixed methods ( } \mathrm{n}=29 \text { questionnaire, } \mathrm{n}=7 \\
\text { community discussion groups, } \mathrm{n}=46 \\
\text { consultation event) }\end{array}$ \\
\hline 5. $\quad$ Kenny \& Wurtele (2012) & USA (various) & Secondary analysis (literature review) \\
\hline 6. Kenny (2010) & USA (various) & $\begin{array}{l}\text { Longitudinal quantitative program evlauation ( } \\
\mathrm{n}=105 \text { children; } 97 \text { parents) }\end{array}$ \\
\hline 7. $\quad$ Krahe \& Knappert (2009) & Germany & $\begin{array}{l}\text { Longitudinal group-randomised program }(\mathrm{n}= \\
148 \text { children })\end{array}$ \\
\hline \multicolumn{3}{|l|}{ Based in non-Western contexts } \\
\hline 8. Chen et al (2007) & China & $\begin{array}{l}\text { Large representative quantitative sample ( } \mathrm{n}= \\
652 \text { parents) on prevention attitudes, } \\
\text { knowledge and communication }\end{array}$ \\
\hline 9. Chen \& Chen (2005) & China & $\begin{array}{l}\text { Cross-sectional quantitative survey on } \\
\text { prevention knowledge, attitudes and practices } \\
\text { (n = } 385 \text { parents) }\end{array}$ \\
\hline 10. Gibson et al. (2007) & Jamaica & Secondary analysis (literature review) \\
\hline
\end{tabular}




\begin{tabular}{|l|l|l|}
\hline 11. Ige \& Fawole (2011) & Nigeria & $\begin{array}{l}\text { Quantitative survey of prevention practices (n } \\
387 \text { parents) }\end{array}$ \\
\hline $\begin{array}{c}\text { 12. Samms \& Cholewa } \\
(2014)\end{array}$ & Jamaica & Literature review \\
\hline
\end{tabular}

